\title{
Leadership in higher education: social and communication aspects of the university image
}

\author{
Anastasia Semenova \\ Herzen State Pedagogical University of Russia \\ 48 Moyka Emb., 191186, Saint Petersburg \\ Russian Federation \\ e-mail: semyonovaa@mail.ru \\ Elena Chizhevskaya \\ Industrial University of Tyumen \\ Volodarskogo street 38, 625000 Tyumen \\ Russian Federation \\ e-mail: chizel76@yandex.ru
}

\begin{abstract}
This paper analyses the complex of factors that influence the efficiency of the university activity in terms of image problems. The phenomenon of the image of the university leader (in this case a university rector) is considered by us as a symbolic construct based on a number of socio-psychological determinants.

The paper determines the structure of the image of the university, the stages of managing the image of the university are identified, which are revealed on the grounds of the developed system of communicative integrators. We arrive at a conclusion that certain University integrators act as factors and results of communications and their system includes such aspects as: an integrator-factor (strategic goal); integrator-result (holistic image); integrators of the internal environment of the university; and an integrator as a concept uniting the communicative activity of the university. The work with these integrators is aimed at implementing an updated version of the communicative policy of the university.

Based on our obtained results, we come up with some practical recommendations for managing the image of the university within each of the communicative integrators. Our results might be of special interest for higher education policy planners and regulators.
\end{abstract}

\section{Introduction}

The conceptual apparatus of the image is reflected through the scientific discoveries of specialists in the field of psychology and sociology. The iconic essence of the image is considered in the context of the ideas of symbolic interactionism and theories of social influence (Denzin 2017).

The science of constructing an image, studying and transforming practical conditions, which the image should match, is called imageology. This is a relatively new area of scientific knowledge, the purpose of which is to create methodological equipment for professional activities in creating and transforming the image (Romanovskii 2011).

In Russia, the formation of image as a new field of scientific knowledge began in the 1990s and the image was viewed as a 'visual image' when the development of specialized image technologies was the task. Further, an image was defined as an impression, opinion about the person (organization) in the mind (or subconscious) of other people, where the technological development of specific techniques is central. Now in the Russian literature devoted to the study of image problems, the following directions shape up: i) the one devoted to the development of the foundations of the theory of image, and ii) the one devoted to a complex of applied aspects of the image (Mukhametzyanova et al. 2017).

In sociology, the image means: a) the external picture created by the subject, in order to evoke a certain impression, opinion, attitude among others; b) a set of properties attributed by advertising, propaganda, tradition, etc., to the object in order to cause certain reactions to it. The main characteristics of the phenomenon of image include: a symbolic, active-passive nature; construction and controllability; functionality; complexity; dynamism (Leopold and Mayer 2015). The main functions of social imageology are:

- $\quad$ study of the role and functions of images in the social and communicative space, methods of managing various images;

- creation of social technologies for image management, development of specialized image technologies. 
The image, as a phenomenon of the communicative environment, is based on symbolic nature. Image is the most economical way of generating and recognizing complex social reality, the result of information processing. Image is not just a mental notion of consciousness as a reflection of reality, it is a specially modeled purposeful 'reflection of reflection' (reflection of an image, already created by professionals based on some reality).

There are several components of the image: some 'source material', pretreated to minimize its negative and maximize the positive features in accordance with the basic parameters of the optimal image model; the chosen model of image; inevitable distortions introduced by image translation channels; the result of active mental work of the audience on the reconstruction of the integral final image in his mind.

These components can also be represented as the process of idealized design of the image of any social organization, which consists of two parts: idealization (formulating threats and opportunities, planning image policy objectives) and implementation (planning resources, project implementation, project image monitoring, process image management). Thus, the variety of formulations in the definition of the concept under study allows us to identify some common features: the image exists as a totality of representations in public opinion; image is a construct that is created through the use of special technologies (Moskalenko and Yevsieieva 2015; Strielkowski et al. 2018).

The methodology of this paper is based on the role of symbols and meanings in the sociological theories of Herbert George Blumer and Talcott Parsons. Thus, we argue that the symbol is involved both as a tool and as a result in a system of social interactions. Therefore, we considered the symbolic basis of the image as an instrument and as a result in the system of social interactions. Two sociological theories are singled out, which allow analyzing the phenomenon of image together with such categories as: symbol, meaning, impression, social interaction, interpretation, expectation. We draw attention to the fact that the image is not seen as a way of manipulating the public consciousness, despite the strong potential of information impact.

The problem posed in this study involves addressing to several groups of scientific sources - image problems, the concept of 'social technology', the phenomenon of leadership. Let us consider the basic approaches to the disclosure of the 'social technology' and 'image' concepts' essence. The term 'technology' was introduced into the scientific revolution at the end of the $18^{\text {th }}$ century specifically to designate a set of methods for processing raw materials and semi-finished products (Perez 2010).

\section{The scope of the university image}

The modern market of educational services and increased competition among educational institutions creates the need to apply successful practices of managing the image of the university through its graduates (Bordea et al. 2017; or Bordean and Sonea 2018). Granting greater autonomy to higher educational institutions makes it possible to design or strengthen image policy for universities, to develop effective models of interaction with interested groups (Bogdanović et al. 2018; or Strielkowski 2018). There are a number of studies devoted to the actual problems of the university's image and its formation (see e.g. Baloglu et al. 1999; Kazoleas et al. 2001; Aghaz et al. 2015; or Schlesinger et al. 2017).

A fairly large number of publications have been published that examine both the phenomenology of the image in general and the problems of managing the image of universities in particular. The image of the university is a public perception of the university, formed based on the experience of personal communication with the educational institution, as well as by the mass media (see e.g. Delmestri et al. 2015). Moreover, a favorable image is the main source of competitive attractiveness and popularity of universities in the eyes of potential applicants. Experts consider the main elements of the system image of the university as follows: the image of the educational service, which consists of the unique characteristics of the product/service represented by the institution (or ideas about them), for example, the received specialty as a certain value, the desire to occupy a high social position after graduation, conditions of payment or admission at the budget costs (Watkins and Gonzenbach 2013; or Yuan et al. 2016).

Particularly there should be emphasized that the different forms of ownership of universities, different positions in the system of higher education and different places in international and Russian rankings of higher education institutions have a significant impact on the image of the university as a whole:

- image of consumers of educational goods (services) includes their social status, standard of living;

- the internal image of the university;

The internal image of the university includes the presentations of teachers and students about the university, the image of the offered educational services. The main determinants of the internal image are the corporate culture of the organization as a set of values and norms shared by the university staff, as well as the socio-psychological climate. The creation of a positive internal image of the university is largely due to the implementation of activities aimed at existing local cultures within the official corporate culture of the university (for example, KVN (an abbreviation stands for "Club of the Funny and Inventive People"), initiation into 
students, Olympiads, competitions, etc.). Such activities are designed to fulfill a dual function: to strengthen the educational institution internally and create a 'team' of like-minded people working with a clear understanding of common goals and interests. These events actively contribute to strengthening the external positions of the university, increasing its prominence in the public eye.

The internal image contains many components, for example: the mission and history of the university, the location and architectural structure of the building, the design of the premises, the spaciousness and comfort of the classrooms, organizational culture, personnel management, the educational environment and its sociopsychological climate, etc. The image of the head of the university and the visual image of the university (the interiors of the building, the symbols of the university, the appearance of teachers and students), the image of teachers and students of the university (professional competence, culture et al.) should be particularly mentioned.

The external image of the university is very closely connected with applicants, the state, the public, partner universities through the implementation of various projects with the participation of consumers of educational services (for example, the development of its own website, Open Days, school attendance, etc.).

The external target audience includes the state, applicants, employers, universities-partners, and the public. It is important for the state that the quality of graduates' education meets the requirements of state educational standards, so that universities make an adequate contribution to the development of the scientific and research potential of the region, act as partners of public authorities in addressing urgent socio-economic and scientific-technical problems.

It is important to have this information in open access, understandable and attractive for school graduates. For successful interaction with employers, it is important to consider the following factors: practice-oriented training of students, a positive academic reputation and innovative activity of the university.

Applicants are primarily interested in the information about the university. They are interested in what exams to pass to enter the university, what directions are offered by the university, what is the USE (Unified State Exam) passing score for the main educational programs (or faculties) that they will choose. It is important that this information is in open access, understandable and attractive for school graduates. For successful interaction with employers, it is important to consider the following factors: practice-oriented training of students, a positive academic reputation and innovative activity of the university.

One of the main indicators of the success of the management process of the university's image is the number of applicants applying for a single competitive place, which makes it possible to judge the relevance of a particular specialty.

Some specialists separate the social image, which is broadcast through the education and upbringing of young people, the implementation of scientific activities, participation in major regional projects, etc., and the business image of the university (which is based on the volume of money from the sale of educational services, the innovation of educational technologies, etc.).

Then the construct of the image of the university in the communicative space is one of the mechanisms that can reduce the distance between the university and target audiences and establish communication with the public.

An important component of the image is also the style of business relations, the location of the building, architectural and interior design, and landscaping are also of importance. The content of the image policy of the university is the creation of effective communications with target audiences both inside and outside the university. At the same time, the university needs to decide on the communication channels for the most effective impact on target groups, both internal (students, faculty) and external (public, applicants, partner universities, employers and the state).

Teachers are interested in comfortable working conditions and research possibilities. At universities, an effective system is needed to enhance the professional qualifications of the teachers and to exchange experience in teaching activities. These are the tools to enhance the image of the university. To develop partnerships with Russian and foreign universities, the universities need to develop international relations (holding international conferences, attracting foreign teachers, foreign students, etc.). In addition to working on development of educational programs in foreign languages, universities must improve their infrastructure (cozy hostels, material and technical facilities), create organized student leisure to adapt to the Russian educational system of foreign students, develop and implement programs for student interaction with local communities.

Consequently, in the structure of the university's image, there are groups of external and internal public that form the external and internal image of the university as a complex social system:

- $\quad$ external image (state, applicants, employers, universities-partners, etc.);

- internal image (mission and history of the university, location and architectural structure of the building, design of premises, spaciousness and convenience of classrooms, organizational culture, personnel management, educational environment and its socio-psychological climate, etc.). 
Separately, it is necessary to highlight the image of the head of the university, the image of teachers and students of the university. The role of the leader - the rector of the university is undoubtedly the most important in the university. The rector of the university is a figure of an elite disposition. It is he who, as the leader, determines the direction of development and the goals for the entire educational institution. It is he who leads the whole team. The attraction of the educational institution largely depends on the authority of the rector, the uniqueness of the faculty, the availability of doctors and candidates of sciences, professors, academicians, their fame, and the credibility of them. Not surprisingly, business structures that are dissatisfied with the quality of education of graduates - their employers, cooperate with universities, jointly modernize educational programs, methods of teaching. And here is a key role of the rector in the dialogue with the main employers and creation of a new quality communication environment, improving the reproduction of highly professional personnel for business. He has to participate in coordinating the requirements of employers to train newly recruited target students, attract large companies to participate in examination boards, job fairs, career days, organize competitions of scientific works on the specialization of employers who establish nominal scholarships for winners of competitions.

\section{Forming a positive university image}

The mechanism for developing and implementing the image policy of the university is presented in four stages:

- development of a program for forming the image of the university;

- design and implementation of a plan of measures to create a positive image of the university for the promotion of its educational services;

- monitoring the results of the implementation of image policy by identifying a constructed (ideal) image comparing with the actual one;

- correction of image policy taking into account the identified assessments and opinions of interested groups.

In order to create a positive image within the university it is necessary to create a favorable educational environment. An important role is played by the bodies of student self-government. Thus, the limits of the transformation of the image of the university are directly related to monitoring and maintaining the image. If regular analysis and evaluation of the image is carried out, maintaining and developing a positive image of the university at the current level is possible. In our opinion, the generalized algorithm for forming and changing the image can contain the following stages:

Stage 1. Forming image purposes.

Stage 2. Analyzing the target audience. At this stage, quantitative and qualitative research of the image audience is carried out. compiled.

Stage 3. Drawing image characteristics. A list of the qualities to be broadcast to the image audience is

Stage 4. Comparing existing and desired characteristics. As a result of this analysis, three lists of characteristics are formed:

1) the characteristics available for the object's self-presentation of the image and working on the image being created, they need to be strengthened and demonstrated;

2) the characteristics available for the object's self-presentation, but reducing or even destroying the image created (they must be disposed of);

3) the characteristics necessary to create an image, but not available at the present time. goals).

Step 5. Selecting self-presentation tools (selection of specific techniques aimed at achieving image

Stage 6. Implementing the image.

The main directions of forming a positive image of the university in the international educational environment are:

- $\quad$ establishment of long-term mutually beneficial direct contacts with foreign educational institutions, as well as international organizations, foundations, non-profit organizations;

- development of the academic mobility system of the faculty, students and management staff of the university;

- intensification of work on registration of applications for international projects and grants;

- expansion and intensification of international research and innovation activities of the university;

- maintenance of cooperation with universities of other countries, connected with the creation of international joint scientific and educational structures on the basis of the university; 
- development of joint educational programs at the university with a double diploma as the most important means of increasing the competitiveness of the university in the market of educational services;

- development of the postgraduate education system for foreign students, development of short-term programs, summer schools; granting the possibility of passing pre-diploma practice;

- improvement of the quality of life and safety of foreign students;

- development and introduction of proposals for the opening of organizational structures at partner universities that popularize knowledge about the university, culture and history of the peoples of the country and thereby contribute to the enhancement of the positive image of the university abroad.

Thus, the image policy is an important tool for the management of the university and the mobilization of its resource potential. The content of the image policy of the university is the creation of effective communications with target audiences both within the university (students and teachers) and in the external environment (university entrants, the state, the public, partner universities) through the implementation of various projects with the participation of consumers of educational services, Open Days, school visits, etc.). In this case, the institution needs to determine the choice of communication channels for the most effective impact on target groups.

For a comprehensive study of the image of the university, it is necessary to use more widely the methods of sociological research that allow us to detect discrepancies in the image estimates; to carry out the analysis of social media for determining the risk zone in managing the image of the university; to conduct content analysis of the media, helping to identify problems of interaction between the university and its target audiences.

\section{Image management of the university as a social and communication technology}

Managing the image of the university assumes, first of all, working on management of communication. Managing communication means solving at least seven tasks:

- define the objectives of communications;

- form ways and means to achieve these goals;

- design and plan taking into account resources, the situation; the partners, specific communication tactics leading to achievability (organizational success, dependent on both intra-organizational communications and contacts with the external environment);

- $\quad$ organize the implementation of these plans;

- coordinate the interaction of the components of the communication process, as well as the actions of direct executors;

- monitor the quality of communications;

- $\quad$ adjust the process based on the results of communication, based on feedback.

Management of the image of the university includes the development of a system of communicative integrators and activities for their implementation in the public consciousness. As we have already explained, the image of the university has a certain structure, which consists of interacting elements. Then, from the viewpoint of the system approach, a holistic image is represented by a system whose elements are integrated into a united whole by communicative integrators. The communicative integrator is the factors and results of communications in the communicative space of the university that are long-term in nature and influence the internal and external public by uniting them around the university.

It is necessary to have all the activities of the university integrated on the basis of communicative integrators, they should be recognized and accepted as necessary conditions for the integrity of the system. The system of communicative integrators is the basis of the socially communicative technology of managing the image of the university, which is able to influence the social reality on a regional scale.

The purpose of working with communicative integrators is the formation and management of the communicative space of the university, which in turn affects the increase of interest, public confidence, and the strengthening of its positive image. The increasing role of the communicative interactions of the university leads to a gradual realization of the need for its communicative competence to study the diverse processes that occur at the level of constructing reality through communicative actions. Then the communicative competence of the university can be defined as the degree of mastering the forms of constructing a socially communicative functional space by the university, both inside and outside. Communicative competence of the university should be considered as a significant characteristic of its managerial potential. 
The purpose of working with communicative integrators is the formation and management of the communicative space of the university. Accordingly, the management of the image of the university is impossible without its communication provided by the system of communicative integrators.

In our opinion, image management is possible only with high-quality image self-control of behavior by the university itself, which presupposes the organization of a selection committee, a career development center, a marketing department of the university, and work on organizing practices at a high level. If the management of the university monitors factors that block a positive image, and factors that contribute to the image, along with financial and other indicators, then the formed 'image ideology' contributes to the achievement of strategic goals by the university.

Having considered the above definitions, we will denote the essence of social technology in a broad sense. Social technology is a purposeful activity of a social subject based on a definite plan, aimed at solving a socially significant task and representing a system of operations for the use of social resources that ensures the solution of this task. Social technology is the impact on the social organization with the aim of optimizing it in a certain managerial aspect. Consequently, the socially communicative technology of managing the image of the university aims to form and subsequently strengthen the positive image by strengthening its social capitalization. Socio-communicative technology of management of the university's image allows revealing the management possibilities of each communicative integrator.

\section{Conclusions}

Overall, it appears that the possibilities of the image policy of the university are directly related to the management activity of the university as a whole and the mobilization of its resource potential. Image management is based on the development of effective communications with target audiences both inside the university (students and teachers) and outside (applicants, the state, the public, partner universities) through the optimization of their web site, the well-considered program of the Open Doors Days, visits to schools etc., i.e. with the participation of consumers of educational services. Such a work will help to identify the discrepancies in the image and risk assessment in the management of the university's image.

The stages of managing of the university's image involve working with communicative integrators and include: analysis and assessment of the current state of the image; forecasting and adoption of possible actions to transform the image; generalization of management activities; evaluation of the updated image; planning prospects for further image changes. It is revealed that the most favorable conditions for the university are those when the rector, its official leader, is also a recognized leader of the university community, and is characterized by self-confidence as an integral quality of the leader. This characteristic is the most important 'soft' competence, demanded in the work of a modern leader. Leadership potential of the university head is a fundamental resource for effective and stable university's movement forward.

\section{References}

Aghaz A, Hashemi A, Sharifi Atashgah MS (2015) Factors contributing to university image: the postgraduate students' points of view. Journal of Marketing for Higher Education 25(1):104-126. doi: 10.1080/08841241.2015.1031314

Baloglu S, McCleary KW (1999) A model of destination image formation. Annals of tourism research, 26(4), 868-897. doi: 10.1016/S0160-7383(99)00030-4

Bogdanović M, Vetráková M, Filip S (2018) Dark triad characteristics between economics \& business students in Croatia \& Slovakia: what can be expected from the future employees? Entrepreneurship and Sustainability Issues 5(4): 967-991. doi:10.9770/jesi.2018.5.4(19)

Bordea E, Manea M, Pelligrini A (2017) Unemployment and coping with stress, anxiety, and depression. Czech Journal of Social Sciences, Business and Economics 6(2):6-14. doi: 10.24984/cjssbe.2017.6.2.1

Bordean ON, Sonea A (2018) Student satisfaction and perceived skills: any link to employability? Entrepreneurship and Sustainability Issues 6(1): 356-370. doi: 10.9770/jesi.2018.6.1(22)

Delmestri G, Oberg A, Drori GS (2015) The unbearable lightness of university branding: Cross-national patterns. International Studies of Management \& Organization 45(2):121-136. doi: 10.1080/00208825.2015.1006012

Denzin NK, Sociological methods: A sourcebook, $1^{\text {st }}$ edn. (Routledge, London, 2017), 600 p. 
Kazoleas D, Kim Y, Anne Moffitt M (2001) Institutional image: a case study. Corporate Communications: an international journal, 6(4), 205-216. doi: 10.1108/EUM0000000006148

Leopold C, Mayer RE (2015) An imagination effect in learning from scientific text. Journal of Educational Psychology 107(1):47-63. doi: 10.1037/a0037142

Moskalenko V, Yevsieieva I (2015) Effective leadership conflict management in food technology enterprises. International Economics Letters 4(2):91-102. doi: 10.24984/iel.2015.4.2.4

Mukhametzyanova LY, Bezborodova MA, Korzhanova AA, Akhmetov LG, Sotnikov, MV, Khairullina ER (2017) Formation of students emotional intelligence as a factor of their academic development. Man in India 97(3):543-552.

Perez C (2010) Technological revolutions and techno-economic paradigms. Cambridge journal of economics 34(1):185-202. doi: 10.1093/cje/bep051

Romanovskii NV (2011) Contemporary Sociology: The Determinants of Changes. Sociological research 50(1):78-95. doi: 10.2753/SOR1061-0154500105

Schlesinger W, Cervera A, Pérez-Cabañer C (2017) Sticking with your university: the importance of satisfaction, trust, image, and shared values. Studies in Higher Education 42(12): 2178-2194. doi: $10.1080 / 03075079.2015 .1136613$

Strielkowski W, Kiseleva L, Popova E (2018) Factors determining the quality of university education: students' views. Integration of Education 22(2):220-236. doi: 10.15507/1991-9468.091.022.201802.220-236

Strielkowski W (2018) A postdoc's purpose. Science 360(6384):27-27. doi: 10.1126/science.aat6008

Yuan R, Liu MJ, Luo J, Yen DA (2016) Reciprocal transfer of brand identity and image associations arising from higher education brand extensions. Journal of Business Research 69(8):3069-3076. doi: 10.1016/j.jbusres.2016.01.022

Watkins BA, Gonzenbach WJ (2013) Assessing university brand personality through logos: An analysis of the use of academics and athletics in university branding. Journal of Marketing for Higher Education 23(1):15-33. doi: 10.1080/08841241.2013.805709 